\title{
Relationship between Crystalline Size, Activity and Expansive Properties of MgO Expansive Agent
}

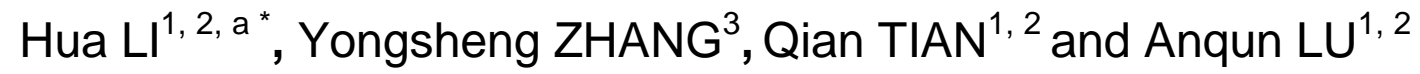 \\ 1Jiangsu Sobute New Materials Co., Ltd., Nanjing 211103, China; \\ ${ }^{2}$ State Key Laboratory of High Performance Civil Engineering Materials, Jiangsu Research Institute \\ of Building Science, Nanjing 210008, China; \\ 3 Jiangsu Provincial Transportation Engineering Group Co., Ltd., Zhenjiang 212016, China \\ alihua@cnjsjk.cn
}

Keywords: MgO expansive agent; calcination temperature; crystalline size; activity; expansive property

Abstract. The quantitative relationships between the calcination temperature and the crystalline characterization, the activity and the expansive properties of $\mathrm{MgO}$ expansive agent were explored through XRD-Scherrer formula, the citric acid method and the length measurement method. The results show that, under the same heat preservation time conditions, there exists exponential relationship between crystalline size and calcination temperature of $\mathrm{MgO}$ expansive agent, and exists linear relationship between the activity value of $\mathrm{MgO}$ expansive agent and the crystalline size of $\mathrm{MgO}$ crystal. Before 28 curing days, the expansion ratios of cement pastes possess logarithmic relationship with the activities of $\mathrm{MgO}$ expansive agent, while with the increase of curing age, specimens containing $\mathrm{MgO}$ of high activity values show faster increase rates in expansion ratio in 60 180d, and the relationship between the expansion ratio and the activity value of $\mathrm{MgO}$ expansive agent becomes more complicated.

\section{Introduction}

Using the delayed expansion property of $\mathrm{MgO}$ to compensate the temperature shrinkage of concrete has been successfully applied in several mass concrete structures such as dams, diversion tunnels and so on $[1,2]$. But there still exists many controversies on the expansion properties and stability of $\mathrm{MgO}$ expansive agent in the actual use [3-5]. Since the $\mathrm{MgO}$ expansive agent is calcined by magnesite, its expansion property is significantly affected by the thermal history in calcination process. Many studies have shown that the calcining temperature is the most important factor influencing the reactivity and expansion property of $\mathrm{MgO}$ [6-8], but the specific relationship is still not very clear. In this paper, the quantitative relationships between the calcination temperature and the crystalline characterization, ther activity and the expansive properties of $\mathrm{MgO}$ expansive agent were explored, which can provide a reference for the preparation and application of $\mathrm{MgO}$ expansive agent.

\section{Raw Materials and experimental Methods}

Preparation and basic performance of MgO expansive agent. The $\mathrm{MgO}$ expansive agent used here was laboratory-calcined under different calcination temperatures and the same heat preservation time, with the chemical compositions shown in Table 1. As can be seen from Table 1, the chemical compositions of $\mathrm{MgO}$ expansive agent under different calcination temperatures are basically the same, with the $\mathrm{MgO}$ component accounting for more than $90 \%$. The particle size distribution tested by the laser particle size analyzer is shown in Fig. 1. As seen from Fig. 1, the particle size distributions of $\mathrm{MgO}$ expansive agent under different calcination temperatures are substantially the same.

Testing methods. The activities of $\mathrm{MgO}$ expansive agent were tested by the citric acid method according to DL/T 5296-2013 [9], in which, the longer the time represents the lower the activity. The crystalline sizes of MgO were tested by Bruker-AXS D8 DISCOVER X-ray diffractometer equipped with the LynxEye array detector, at a work condition of $\mathrm{Cu}$ target, $40 \mathrm{kV}$ operating voltage, $35 \mathrm{~mA}$ 
operating current, $4.0^{\circ}$ sola slit, $10-80^{\circ} 2 \theta, 0.02^{\circ}$ step size and $0.2 \mathrm{sec} / \mathrm{step}$. Compress the powder to a glass sample plate special for the diffractometer, after instrumental parameters being adjusted, insert the glass sample plate into the sample holder and test. Then the crystalline sizes of $\mathrm{MgO}$ were calculated by Scherrer formula $\mathrm{D}_{\mathrm{hkl}}=\mathrm{K} \lambda /\left(\beta_{\mathrm{hkl}} \cos \theta_{\mathrm{hkl}}\right)$, in which $\mathrm{K}$ representing Scherrer constant with the value being $0.89, \lambda$ representing the $\mathrm{K} \alpha 1$ wavelength of $\mathrm{X}$-ray being $0.154056 \mathrm{~nm}$ here; $\beta_{\mathrm{hkl}}$ representing the broadening of (hkl) diffraction peak, in this paper calculated by $\beta=\mathrm{B}-\mathrm{b}$ (B being FWHM, half the width of the (hkl) diffraction peak, rad; b being the width of the instrument, here taking $\left.0.140^{\circ}\right) ; \theta_{\mathrm{hkl}}$ representing the diffraction angle of (hkl) crystalline faces. The deformation properties of cement pastes mixed with $4 \%$ (mass fraction) $\mathrm{MgO}$ expansive agent were tested using prism specimens with the size of $25 \mathrm{~mm} \times 25 \mathrm{~mm} \times 280 \mathrm{~mm}$ in which copper head buried at both ends, after pouring the specimens were conserved under $(20 \pm 1)^{\circ} \mathrm{C}$ for $(24 \pm 2) \mathrm{h}$ with the surface of the specimen covered by PVC plastic film, then removing the mould, and measured the initial length $\mathrm{L}_{0}$ of each specimen $1 \mathrm{~h}$ later, after that, the specimens were placed in water under $(20 \pm 1)^{\circ} \mathrm{C}$ and measured the length $\mathrm{L}_{\mathrm{n}}$ at each age. Expansion coefficient $\varepsilon$ was calculated by the formula $\varepsilon=\left(\mathrm{L}_{\mathrm{n}}-\mathrm{L}_{0}\right) / \mathrm{L} * 100 \%$, wherein the effective length $\mathrm{L}=250 \mathrm{~mm}$.

Table 1 Chemical compositions of $\mathrm{MgO}$ expansive agent under different calcination temperatures. \%

\begin{tabular}{|c|c|c|c|c|c|}
\hline Calcination temperature-heat preservation time & $\mathrm{MgO}$ & $\mathrm{SiO}_{2}$ & $\mathrm{CaO}$ & $\mathrm{Fe}_{2} \mathrm{O}_{3}$ & $\mathrm{Al}_{2} \mathrm{O}_{3}$ \\
\hline $800^{\circ} \mathrm{C}-1 \mathrm{~h}$ & 90.4 & 4.23 & 3.01 & 1.23 & 0.762 \\
\hline $850^{\circ} \mathrm{C}-1 \mathrm{~h}$ & 91.1 & 3.85 & 3.01 & 1.13 & 0.58 \\
\hline $900^{\circ} \mathrm{C}-1 \mathrm{~h}$ & 90.9 & 4.01 & 3.03 & 1.10 & 0.63 \\
\hline $950^{\circ} \mathrm{C}-1 \mathrm{~h}$ & 90.9 & 4.03 & 2.98 & 1.07 & 0.69 \\
\hline $1000^{\circ} \mathrm{C}-1 \mathrm{~h}$ & 91.1 & 3.88 & 3.01 & 1.00 & 0.36 \\
\hline $1050^{\circ} \mathrm{C}-1 \mathrm{~h}$ & 91.0 & 3.84 & 3.07 & 1.13 & 0.67 \\
\hline
\end{tabular}

Note: Some components of which the content $<0.05 \%$ have been discarded.

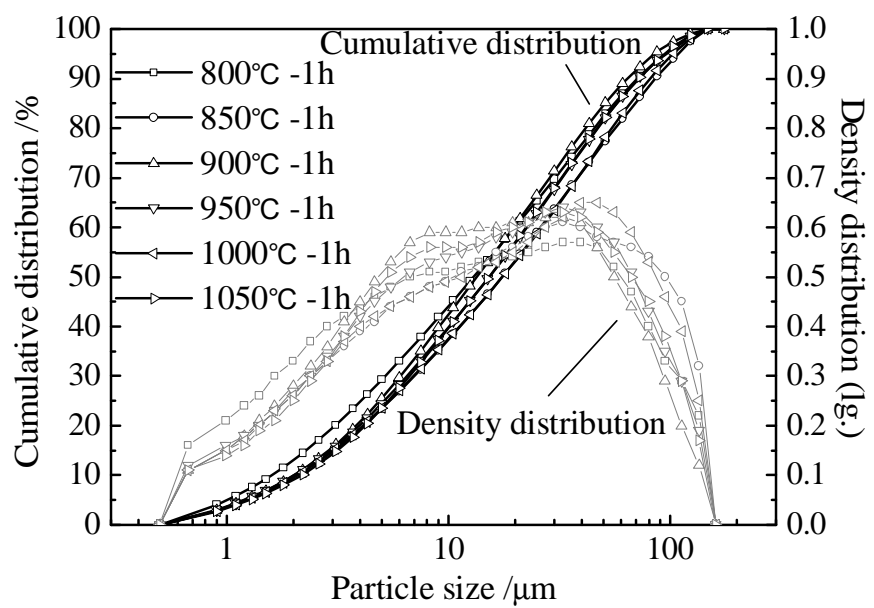

Fig. 1 Cumulative and density distributions of $\mathrm{MgO}$ expansive agent.

\section{Results and discussion}

The crystalline size of the calcined MgO. The XRD patterns of $\mathrm{MgO}$ expansive agent obtained from different calcination temperatures and the same heat preservation time are shown in Fig. 2. As can be seen from Fig. 2, the higher the calcination temperature, the sharper the $\mathrm{MgO}$ diffraction peaks, which indicates that the higher the degree of crystallinity. XRD professional analysis software was used to analyze the patterns, and the obtained diffraction angle $2 \theta$ and full width at half maximum (FWHM) of 
(2 0 0 $)$ diffraction peak of $\mathrm{MgO}$ are shown in Table 2. Then the crystalline sizes of the calcined $\mathrm{MgO}$ were calculated by Scherrer formula and shown in column 5 of Table 2. From Table 2, it can be seen that, the crystalline size of the calcined $\mathrm{MgO}$ increases with the increase of the calcination temperature. Meanwhile, the crystalline sizes of the calcined $\mathrm{MgO}$ were also calculated using Lorentz formula with the results shown in column 6 of Table 2. From comparison of the calculating results by the two methods, it is found that for $\mathrm{MgO}$ expansive agent calcined below $1000^{\circ} \mathrm{C}$, the crystalline size obtained by the two methods are basically the same, while for $\mathrm{MgO}$ expansive agent calcined under $1050^{\circ} \mathrm{C}$, the crystalline size obtained from Lorentz formula is significantly lower than that obtained from the Scherrer formula.

The activity of MgO expansive agents. The activities of $\mathrm{MgO}$ expansive agent tested by the citric acid method are shown in Table 3. As can be seen from Table 3 that, under the same heat preservation time conditions, the activity value of $\mathrm{MgO}$ expansive agent increases with the increase of the calcination temperature, that is, the hydration activity decreases with the increase of the calcination temperature. It can also be seen from Table 3 that, below $950^{\circ} \mathrm{C}$, the calcination temperature has less effect on the activity of $\mathrm{MgO}$; while above $950^{\circ} \mathrm{C}$, the calcination temperature plays a greater effect role on the activity of $\mathrm{MgO}$.

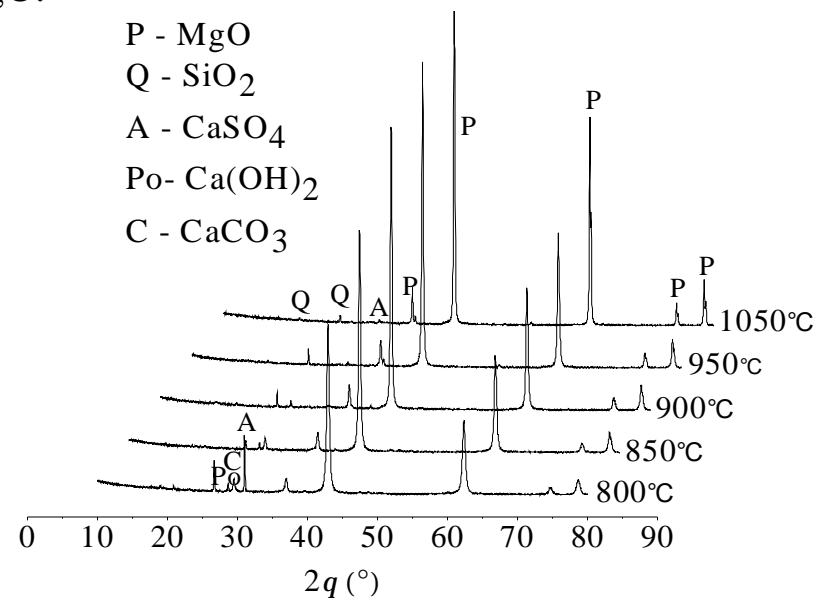

Fig. 2 XRD patterns of $\mathrm{MgO}$ expansive agent obtained from different calcination temperatures.

Table 2 Crystalline features of calcined $\mathrm{MgO}$.

\begin{tabular}{|c|c|c|c|c|c|}
\hline $\begin{array}{l}\text { Calcination temperature- } \\
\text { heat preservation time }\end{array}$ & (hkl) & $2 \theta\left(^{\circ}\right)$ & FWHM $\left(^{\circ}\right)$ & $\mathrm{D}($ Scherrer $)$ & $\mathrm{D}$ (Lorentz) \\
\hline $800^{\circ} \mathrm{C}-1 \mathrm{~h}$ & $\left(\begin{array}{lll}2 & 0 & 0\end{array}\right)$ & 42.931 & $0.410^{\circ}$ & 31.3 & $32.0 \mathrm{~nm}$ \\
\hline $850^{\circ} \mathrm{C}-1 \mathrm{~h}$ & $\left(\begin{array}{lll}2 & 0 & 0\end{array}\right)$ & 42.951 & 0.346 & 41.0 & $41.7 \mathrm{~nm}$ \\
\hline $900^{\circ} \mathrm{C}-1 \mathrm{~h}$ & $\left(\begin{array}{lll}2 & 0 & 0\end{array}\right)$ & 42.951 & 0.284 & 58.6 & $57.3 \mathrm{~nm}$ \\
\hline $950^{\circ} \mathrm{C}-1 \mathrm{~h}$ & $\left(\begin{array}{lll}2 & 0 & 0\end{array}\right)$ & 42.931 & 0.266 & 67.0 & $65.5 \mathrm{~nm}$ \\
\hline $1050^{\circ} \mathrm{C}-1 \mathrm{~h}$ & $\left(\begin{array}{lll}2 & 0 & 0\end{array}\right)$ & 42.949 & 0.188 & 175.9 & $126.4 \mathrm{~nm}$ \\
\hline
\end{tabular}

Table 3 Activity values of $\mathrm{MgO}$ expansive agent under different calcination temperatures.

\begin{tabular}{|c|c|c|c|c|c|c|c|}
\hline Calcination temperature $/{ }^{\circ} \mathrm{C}$ & 800 & 850 & 900 & 950 & 1000 & 1050 & 1200 \\
\hline Activity value $/ \mathrm{s}$ & 50 & 67 & 80 & 104 & 153 & 322 & 360 \\
\hline
\end{tabular}

Expansion properties of cement pastes containing MgO expansive agent. The testing results of deformation properties of cement pastes containing $\mathrm{MgO}$ expansive agent are shown in Fig. 3. As can be seen from Fig. 3, the expansion ratios of cement pastes containing $\mathrm{MgO}$ expansive agent increase 
with the longer of age, while cement pastes containing $\mathrm{MgO}$ of different activity values display different expansion development histories. In the early age, expansion ratio of specimens containing $\mathrm{MgO}$ under calcination temperature below $1050^{\circ} \mathrm{C}$ is larger than that of the reference, while expansion ratio of specimens containing $\mathrm{MgO}$ under $1200{ }^{\circ} \mathrm{C}$ is smaller than that of the reference. But in the late age of the testing period (60 180d), the expansion ratio of specimens containing $\mathrm{MgO}$ under $1200{ }^{\circ} \mathrm{C}$ shows a faster increase rate. The test results indicate that by controlling the activity of $\mathrm{MgO}$ expansive agent, different final expansion ratio and different expansion development histories can be obtained.

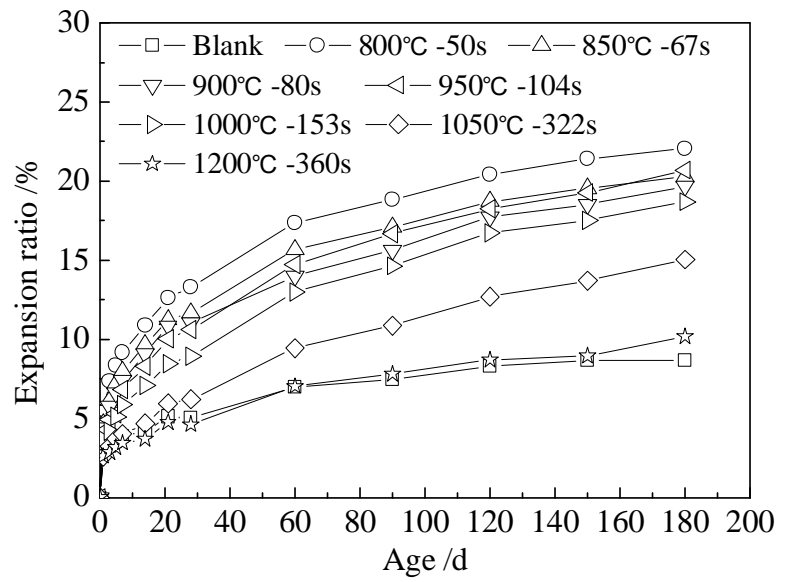

Fig. 3 The expansion curves of cement pastes containing $\mathrm{MgO}$ expansive agent.

Relationship between calcination temperature and crystalline size, activity value of $\mathrm{MgO}$ expansive agent. Relationships between crystalline size, activity value of $\mathrm{MgO}$ expansive agent and calcination temperature are shown in Fig. 4. Relationship between activity value of $\mathrm{MgO}$ expansive agent and crystalline size of $\mathrm{MgO}$ crystal is shown in Fig. 5. From Fig. 4, it is known that there exist simple exponential relationships between crystalline size, activity value of $\mathrm{MgO}$ expansive agent and calcination temperature, with the specific relationship being

$\mathrm{C}=0.00051 * \exp (\mathrm{T} / 83.41998)+26.99701$

where $\mathrm{C}$ representing calcination temperature and $\mathrm{T}$ representing crystalline size of $\mathrm{MgO}$ crystal.

As mentioned in section 2.1, the chemical compositions and the particle size distributions of $\mathrm{MgO}$ expansive agent used here under different calcination temperatures are basically the same, so it can be considered that the activity of $\mathrm{MgO}$ expansive agent relates only to the crystal structure of $\mathrm{MgO}$ crystal. And as shown in Fig. 5, there exists simple linear relationship between the activity value of $\mathrm{MgO}$ expansive agent and the crystalline size of $\mathrm{MgO}$ crystal, with the specific relationship being

$\mathrm{A}=-18.72069+1.91708 \mathrm{C}$

where $\mathrm{C}$ representing crystalline size of $\mathrm{MgO}$ crystal and $\mathrm{A}$ representing the activity value of $\mathrm{MgO}$ expansive agent. 


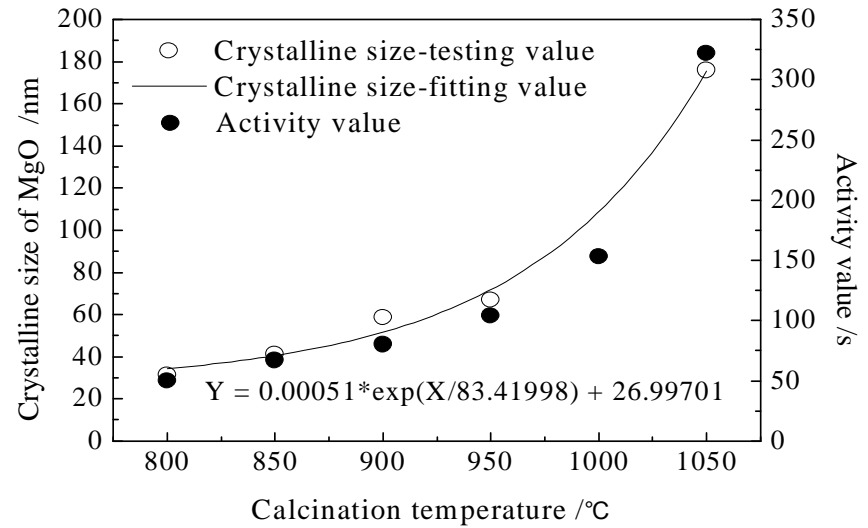

Fig. 4 Relationship between crystalline size, activity value and calcination temperature of $\mathrm{MgO}$ expansive agent.

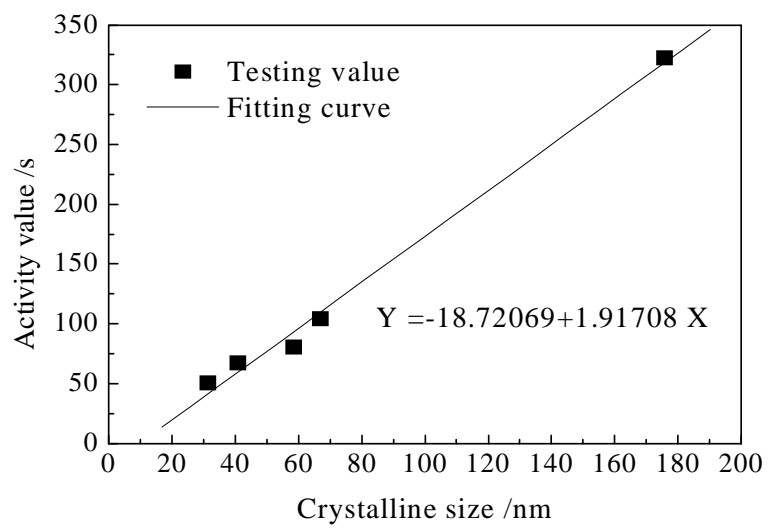

Fig. 5 Relationship between activity value of $\mathrm{MgO}$ expansive agent and crystalline size of $\mathrm{MgO}$ crystal.

Relationship between activity and expansion property of MgO expansive agent. Relationship curves between activities of $\mathrm{MgO}$ expansive agent and expansion ratios of cement pastes containing $\mathrm{MgO}$ expansive agent are shown in Fig. 6. As can be seen from Fig. 6, during the early 28 curing days, there exists simple logarithmic relationship between the expansion ratios of cement pastes and the activities of $\mathrm{MgO}$ expansive agent, and the absolute value of the slope of the curve gradually increases with the extension of curing age. While with the further extension of curing age, specimens containing $\mathrm{MgO}$ of high activity values shows a faster increase rate in expansion ratio in 60 180d, and the relationship between the expansion ratio and the activity value of $\mathrm{MgO}$ expansive agent becomes more complicated, which needs to be further analyzed in the later.

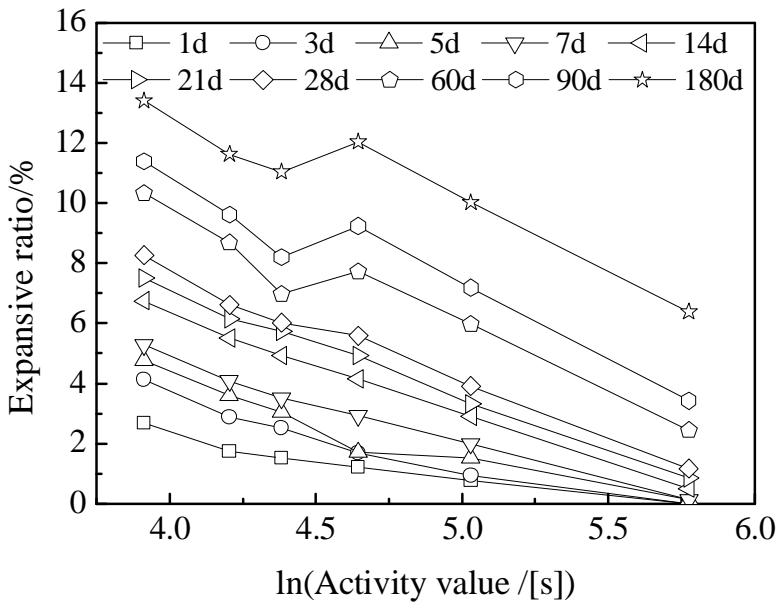

Fig. 6 Relationship curve between activities of $\mathrm{MgO}$ expansive agent and expansion ratios of cement pastes.

\section{Conclusion}

Under the same heat preservation time conditions, there exist simple exponential relationships between crystalline size, activity value of $\mathrm{MgO}$ expansive agent and calcination temperature. Further, controlling the particle size distributions of $\mathrm{MgO}$ expansive agent to be basically the same, there exists simple linear relationship between the activity value of $\mathrm{MgO}$ expansive agent and the crystalline size of $\mathrm{MgO}$ crystal.

There exists simple logarithmic relationship between the expansion ratios of cement pastes before 28 days and the activities of $\mathrm{MgO}$ expansive agent, while with the increase of curing age, specimens containing $\mathrm{MgO}$ of high activity values show faster increase rates in expansion ratio in 60 180d, and 
the relationship between the expansion ratio and the activity value of $\mathrm{MgO}$ expansive agent becomes more complicated.

\section{Acknowledgements}

This work was financially supported by the National Outstanding Youth Science Foundation (51225801), the Science and Technology Plan Project of Jiangsu Province Communications (2015T30), and the Provincial Science and Technology Cooperation Project of Jiangsu Province Jiangsu-Guangxi cooperation project (BM2014050).

\section{References}

[1] CAO Zesheng and XU Jinhua, Construction Technology of Dam with MgO Concrete, China Electric Power Press, Beijing, 2003.

[2] CHEN Changli and TANG Chengshu, The application of $\mathrm{MgO}$ concrete in Dongfeng arch dam foundation and the analysis of long-term prototype observation results, Journal of hydroelectric engineering, 25(4) (2006) 102-107. (in Chinese)

[3] YOU Baokun, Current status and perspective of expansive additive for concrete in China, Concrete, 4 (2003) 3-6. (in Chinese).

[4] ZHAO Shunzeng et al., Current status and future development of expansive agent for concrete, China Concrete and Cement Products, 3 (2009) 1-3. (in Chinese).

[5] MO Liwu et al., MgO expansive cement and concrete in China: Past, present and future, Cem. Concr. Res. 57 (2014) 1-12.

[6] SUN Wenhua et al., Relationship between crystalline size and lattice distortion of $\mathrm{MgO}$ and its activity, Journal of Wuhan University of Technology. 13 (1991) 21-24. (in Chinese)

[7] CUI Xin, DENG Min, Effects of calcined conditions on activity of MgO, Journal of Nanjing University of Technology (Natural Science Edition). 30 (2008) 52-55. (in Chinese)

[8] DU Zhaojin et al., Research on the lattice properties and the expansion properties of $\mathrm{MgO}$ expansive agent, Expansive Agents and Expansive Concrete, 1 (2001) 20-23. (in Chinese)

[9] DL/T 5296-2013 Technical specifications for hydraulic concrete mixed with MgO. 